\title{
The Overall Pattern of Ocular Dominance Bands in Cat Visual Cortex
}

\author{
Patricia A. Anderson, ${ }^{a}$ Jaime Olavarria, ${ }^{b}$ and Richard C. Van Sluyters \\ School of Optometry, University of California, Berkeley, California 94720
}

This study describes the overall arrangement of geniculocortical input representing the system of cortical ocular dominance bands in layer IV of striate cortex in the adult cat. The pattern of ocular dominance bands was revealed by transneuronal transport of the intraocularly injected tracer wheat germ agglutinin conjugated to horseradish peroxidase (WGA-HRP). Our data indicate that this procedure does not damage the retina and that it results in relatively uniform uptake and transport of the tracer. Using previously published techniques (Olavarria and Van Sluyters, 1983, 1985), both cortical hemispheres of each cat were unfolded, flattened and tangentially sectioned. Analysis of the WGA-HRP labeling patterns in these sections revealed a relatively continuous network of irregularly branching bands in layer IV of area 17 in both hemispheres. Because of a systematic difference in the level of interband labeling, ocular dominance bands appear less distinct in the hemisphere contralateral to the injected eye. There is also a tendency for interband labeling to be greater in cortical regions that represent the more peripheral aspects of the binocular portion of the visual field.

The width of an individual ocular dominance band in the cat fluctuates, so that it appears to be made up of a series of uniformly sized, roughly circular beads of label. The diameter of these beads averages $667 \mu \mathrm{m}$, and preliminary counts indicate that there are $650-675$ beads in each striate cortex. Contrary to earlier suggestions, in 4 out of 6 hemispheres analyzed quantitatively there was no tendency for ocular dominance bands to be oriented along a preferred axis in cat striate cortex, including an axis orthogonal to the border between areas 17 and 18. Ocular dominance bands in area 18 appear to be broader than those in area 17, and they seem to have a greater tendency to be oriented orthogonal to the $17 / 18$ border than those in area 17. Compared with the ocular dominance pattern in monkey striate cortex, the ocular dominance pattern in the cat is much less regular. In general, cat ocular dominance bands appear to

\footnotetext{
Received July 21, 1987; revised Oct. 15, 1987; accepted Oct. 20, 1987.

We wish to thank $M$. Stryker for his encouragement and advice at critical stages of this study, and J. Malpeli and C. Shatz for their helpful comments on the manuscript. We are also very grateful to J. Fiorillo, A. Halperin, P. Lee, and P. Leondis for their skilled technical assistance. This work was supported by research grants to R.C.V.S. from the National Eye Institute (EY02193) and the National Science Foundation (BNS8418738), a postdoctoral fellowship to P.A.A. from the National Eye Institute (EY05621), and a CORE Facilities Support Grant (EY03176) from the National Eye Institute.

Correspondence should be addressed to Richard C. Van Sluyters at the above address.

a Present address: National Science Foundation, 1800 G. Street N.W., Room 320, Washington, D.C. 20550.

Present address: California Institute of Technology, Division of Biology, $216-$ 76, Pasadena, CA 91125
}

Copyright (C) 1988 Society for Neuroscience $0270-6474 / 88 / 062183-18 \$ 02.00 / 0$ fluctuate more in width, to change direction more often, and to be less likely to run orthogonal to the $17 / 18$ border. The greater regularity of the primate ocular dominance pattern may be related to differences in the way in which the visual hemifield is mapped onto the striate cortex in these 2 species.

Neurons in cortical area 17 of the cat and monkey are organized into regions in which their responses to stimuli viewed monocularly are dominated by either the right or left eye. These regions, which extend radially through the gray matter, have been referred to as ocular dominance columns (e.g., Hubel and Wiesel, 1965, 1968). In layer IV of striate cortex, geniculocortical afferents representing the 2 eyes are partially segregated into alternating bands, and these bands have been shown to provide an anatomical basis for physiologically defined ocular dominance columns in this layer (Hubel and Wiesel, 1972; Shatz and Stryker, 1978). The main objective of the present study was to provide a description of the complete pattern of ocular dominance bands in cat visual cortex, a task that has recently been accomplished for striate cortex of the macaque monkey (LeVay et al., 1985).

Several previous anatomical studies have examined ocular dominance bands in layer IV of cat striate cortex (Shatz et al., 1977; LeVay et al., 1978; Shatz and Strykcr, 1978; LeVay and Stryker, 1979; Swindale, 1981; Stryker, 1982; Mower et al., 1985). However, because of difficulties in reconstructing the tangential array of ocular dominance bands from a series of coronal, parasagittal, or horizontal sections through the convoluted cortex, only limited information is available on the overall pattern of these bands (Shatz et al., 1977; LeVay et al., 1978). These previous data are extended by the present study, in which tangential sections through the unfolded and flattened cortex (Olavarria and Van Sluyters, 1983, 1985) are used to reconstruct the complete array of ocular dominance bands in the cat.

In this study, we examine the relationship between the pattern of ocular dominance bands and various features of cortical organization in the cat, including the 2-dimensional shape of striate cortex, the pattern of cortical retinotopy, and the border between areas 17 and 18 . In addition, we compare the overall pattern of ocular dominance columns in the cat to that in the monkey (LeVay et al., 1985) to elucidate possible similarities in the rules governing the formation of this pattern in different species. A preliminary description of the present data was reported in an earlier publication (Anderson et al., 1983).

\section{Materials and Methods}

\section{Intraocular injections of WGA-HRP}

In this study, transneuronal transport of intraocularly injected wheat germ agglutinin conjugated to HRP (WGA-HRP) was used to label 
A
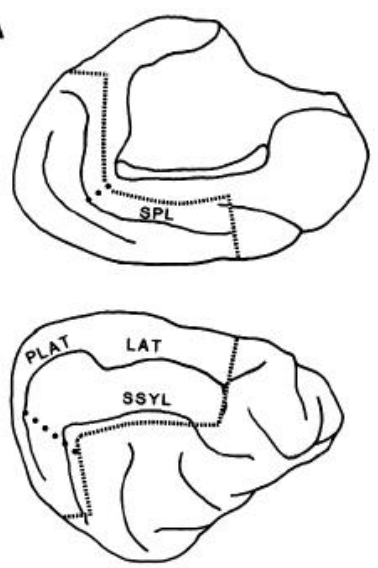

B

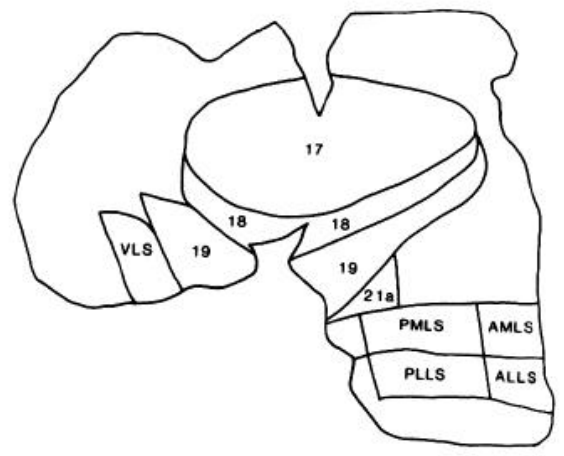

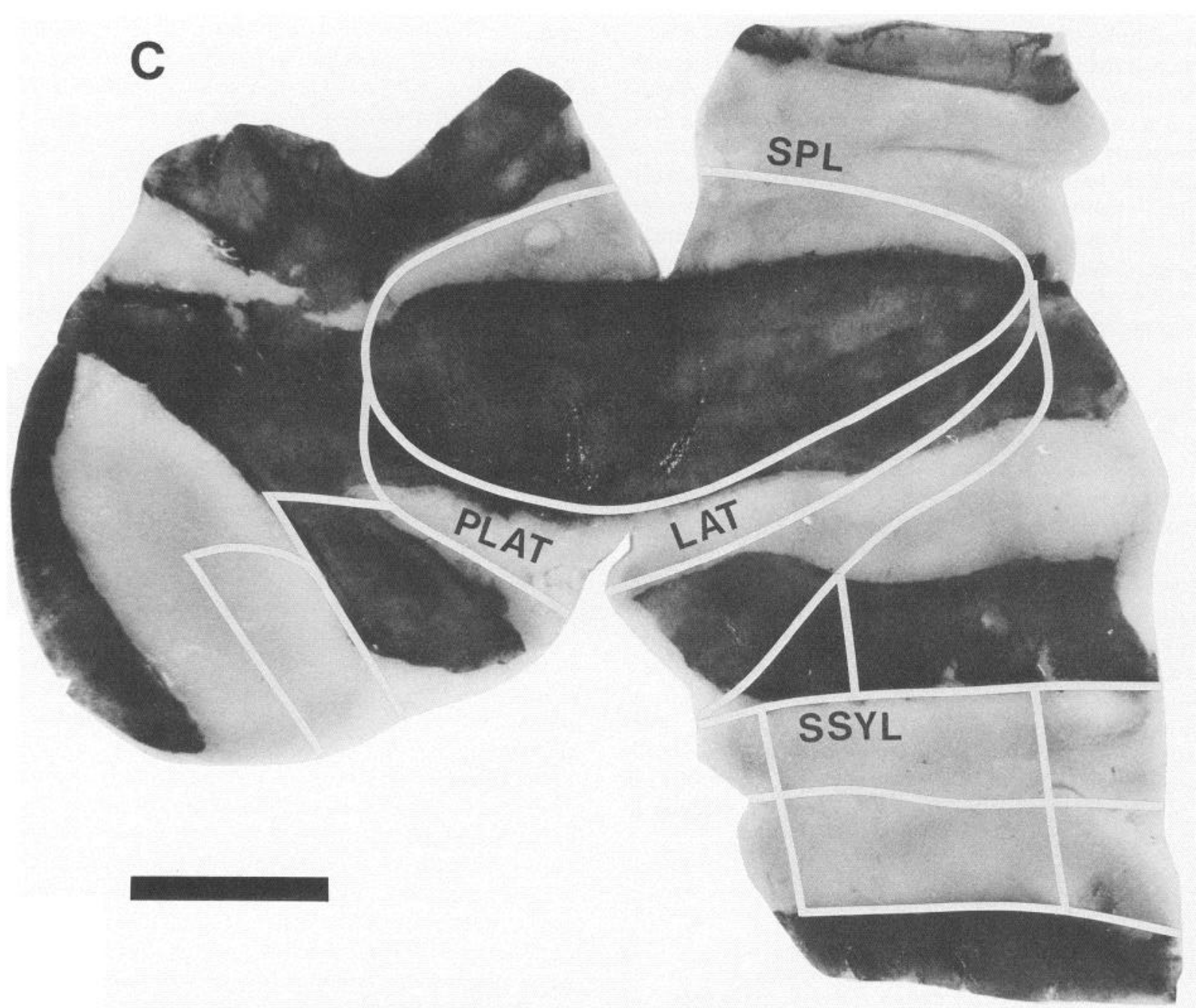

Figure 1. Unfolding and flattening cat cerebral cortex. A, Drawings of medial (top) and lateral (bottom) views of intact cat brain. Interrupted lines indicate extent of the tissue block that was removed and unfolded; dotted lines, locations of cuts made to relieve intrinsic curvature of the brain prior to flattening this block of tissue. SPL, suprasplenial sulcus; $P L A T$, posterolateral sulcus; $L A T$, lateral sulcus; $S S Y L$, suprasylvian sulcus. $B$, Diagram of unfolded and flattened tissue block shown in $C$, indicating the approximate locations of various cortical visual areas on the surface of this block. VLS, ventral lateral suprasylvian; $P M L S$, posteromedial lateral suprasylvian; $A M L S$, anteromedial lateral suprasylvian; $P L L S$, posterolateral lateral suprasylvian; $A L L S$, anterolateral lateral suprasylvian. $C$, Photograph of actual block of unfolded and flattened tissue prior to sectioning. Dark areas are the crowns of gyri that were stained prior to unfolding the cortex; white lines indicate approximate locations of cortical visual areas and were drawn on the basis of gyral landmarks. Same abbreviations as in $A ;$ scale bar, $1 \mathrm{~cm}$. 
thalamocortical terminations in both cerebral hemispheres of 5 normally reared adult cats $(10 \mathrm{mo}--2.5 \mathrm{yr})$ from our mixed-breed closed colony. Cats were anesthetized with halothane (0.5-5.0\%) administered in a mixture of nitrous oxide $(80 \%)$ and oxygen $(20 \%)$. Topical anesthetics were applied to one eye, and $1 \mathrm{mg}$ WGA-HRP (Sigma) dissolved in $20 \mu$ l of normal saline was injected intravitreously over a period of 2-3 min using a $25 \mu \mathrm{l}$ microsyringe. All cats survived $4 \mathrm{~d}$ following an eye injection.

\section{Processing cortical tissue}

Our procedures for unfolding and flattening the cerebral cortex of the cat are described in previous publications (Olavarria and Van Sluyters, 1983, 1985) and are therefore only briefly reviewed here. Cats were deeply anesthetized with pentobarbital sodium and perfused through the heart briefly with normal saline followed by $2 \%$ glutaraldehyde in $0.1 \mathrm{M}$ phosphate buffer ( $\mathrm{pH} 7.4$ ) for 7-8 min. The brain was removed, the dura mater was excised, the cerebral hemispheres were separated from the brain stem, and their surfaces were stained with a dye (see below).

Figure $1 A$ shows drawings of medial and lateral views of an intact hemisphere and the boundaries of the region that were removed for unfolding and flattening. This region included the visual areas that have been described in the posterior neocortex of the cat (e.g., Kahlia and Whitteridge, 1973; Palmer et al., 1978; Tusa et al., 1978, 1979; Tusa and Palmer, 1980). Unfolding and flattening this block of tissue was initiated by incising the arachnoid where it bridges over the sulci and gently opening the sulci. Two cuts (dotted lines in Fig. $1 A$ ) were then made in the margin of the tissue block at locations that were chosen to relieve the intrinsic curvature of the cortex while only minimally intruding into area 17 (see Olavarria and Van Sluyters, 1985). Next, the white matter, which was left quite soft by our initial fixation procedure, was gently removed, allowing the gyri to be unfolded. Finally, the tissue was lightly pressed between 2 glass slides and kept overnight in fixative with $20 \%$ sucrose at $4^{\circ} \mathrm{C}$. The following day, the resulting sheet of tissue (which is about $1.5 \mathrm{~mm}$ thick) was sectioned at $50 \mu \mathrm{m}$ on a freezing microtome.

Sections were reacted for WGA-HRP using the tetramethyl benzidine (TMB) histochemical procedure of Mesulam (1978). In an effort to enhance the intensity of labeling, we used a relatively high concentration of hydrogen peroxide in Solution B $(1 \mathrm{ml}$ of $3 \%$ hydrogen peroxide $/ 200$ $\mathrm{ml}$ solution) and incubated the sections for $30 \mathrm{~min}$. When this resulted in accumulation of excessive amounts of nonspecific precipitates, sections were rinsed briefly in a solution of higher acidity ( $\mathrm{pH} 1.9)$ to help remove these precipitates (see Olavarria and Van Sluyters, 1986).

As mentioned above, a dye was applied to the surface of the intact cerebral hemisphere prior to unfolding the cortical tissue. This was done in order to preserve the gyral pattern of the hemisphere after it had been unfolded and flattened (for details, see Olavarria and Van Sluyters, 1985). Figure $1 C$ gives an example of this pattern for one of the cats from the present study. Knowledge of the gyral pattern for a given hemisphere was helpful in estimating the locations of visual areas in WGA-HRP-labeled tangential sections from that hemisphere (see Figs. 1, $B$ and $C$, and 4).

\section{Processing the retina and visual thalamus}

After the brain was removed from the skull, the visual thalamus was placed in fixative with $20 \%$ sucrose at $4^{\circ} \mathrm{C}$ for $48 \mathrm{hr}$, frozen, and sectioned coronally at $60 \mu \mathrm{m}$. These sections were reacted for WGA-HRP with the same histochemical procedure used for the cortex. In one cat, the eyes were removed from the head immediately following fixation, the anterior segment of each eye was excised, and the vitreous was removed. The posterior segments were kept in fixative at $4^{\circ} \mathrm{C}$ for several days, then trimmed down to 5- to 6-mm-wide horizontal strips that included the entire nasotemporal extent of the retina and contained the optic disk and area centralis. These strips were dehydrated, embedded in glycol methacrylate, sectioned at $3 \mu \mathrm{m}$, and stained with $0.25 \%$ thionin.

\section{Analysis of cortical labeling patterns}

Photomontages. Individual WGA-HRP labeled sections were photographed (Kodak Technical Pan Film) with a 35-mm camera equipped with a bellows and a macro lens, using dark-field illumination and crosspolarization (Illing and Wässle, 1979; Hess and Schneider, 1981). A photomontage of the entire ocular dominance pattern for a given hemisphere was constructed from prints made on high-contrast paper. A given portion of the overall labeling pattern was visible in prints made from several successive tangential sections (e.g., see Fig. 5). The print in which this portion of the labeling pattern appeared most distinct was used to reconstruct the corresponding part of the ocular dominance pattern for that hemisphere. Aligning the ocular dominance bands in adjacent tangential sections was not difficult, and in virtually all cases the matches were unambiguous.

Borders of visual areas. In the present study, several approaches were used to relate the pattern of cortical labeling to the location of various visual areas in the cat brain. For example, features of the WGA-HRP labeling pattern, including its overall extent and changes in the nature of the ocular dominance bands, gave direct information on the location of area 17 (e.g., see Fig. 6). Additional information, derived from a variety of sources, was used to confirm our estimates of the extent of striate cortex and to determine the approximate locations of the borders of extrastriate visual areas. For extrastriate areas, this information included previous descriptions of the relationships between the borders of these areas and the gyral pattern in the intact brain (Palmer et al., 1978; Tusa et al., 1978, 1979; Tusa and Palmer, 1980). When estimating the borders of areas 17 and 18 , we also took advantage of our previous findings on the relationship among cortical myeloarchitecture, visual callosal connections, and the gyral pattern in unfolded and flattened cortical tissue (see Figs. 1 and 4, and Olavarria and Van Sluyters, 1983, 1985).

Area measurements. For 4 cats, a digitizing graphics pad and a computer were used to measure the surface area of striate cortex. These measurements, and all other dimensions reported in this paper, were compensated for tissue shrinkage due to HRP histochemistry. The magnitude of this shrinkage (14-20\%) was estimated by comparing the size of an HRP-reacted section to a photographic record of the size of the unfolded and flattened cortex prior to histochemical processing. We did not compensate for possible shrinkage due to fixation.

\section{Results}

\section{Uptake and transport of WGA-HRP}

To determine whether intraocular injections of WGA-HRP cause damage to the retina, we examined retinal tissue from an injected eye for signs of gross damage due either to the injection or to possible toxic effects of WGA-HRP. Figure 2 shows $3 \mu \mathrm{m}$ sections through the area centralis region of the retinae from the noninjected and injected eyes of one cat. Comparison of these photomicrographs reveals no obvious differences in the number, distribution, or individual appearance of retinal cells in these 2 eyes.

To help assess the uniformity with which WGA-HRP was transported from various regions of the retina to the cortex, we examined the labeling pattern in HRP-tested sections from the thalamus. Figure 3 shows low-magnification bright- and darkfield photomicrographs of a single $60 \mu \mathrm{m}$ section through the left thalamus of a cat whose right eye was injected with WGAHRP. Laminae A, C, and C2 of the dorsal lateral geniculate nucleus (dLGN), which receive direct input from the injected eye, are densely labeled, and, except for the region that contains the representation of the optic disk (arrows in Fig. 3A-C, and see Guillery and Kaas, 1971), the labeling in lamina $A$ is quite uniform. Some reaction product is present in lamina $\mathrm{A} 1$, but the higher magnification dark-field view in Figure $3 \mathrm{C}$ shows that most of it is filamentous in nature, indicating it is confined to fibers of passage. In addition to these labeled fibers, a few larger accumulations of label are present in lamina $A 1$. When viewed al even higher magnification, and under bright-field illumination (Fig. $3 D$ ), these accumulations appear to be either artifact or labeled endothelial cells. Finally, medial to the dLGN, dense labeling is present in portions of both the medial interlaminar nucleus (MIN) and the geniculate wing (GW), which are known to receive direct input from the contralateral retina (e.g., Hayhow, 1958; Guillery et al., 1980; Rowe and Dreher, 1982). 


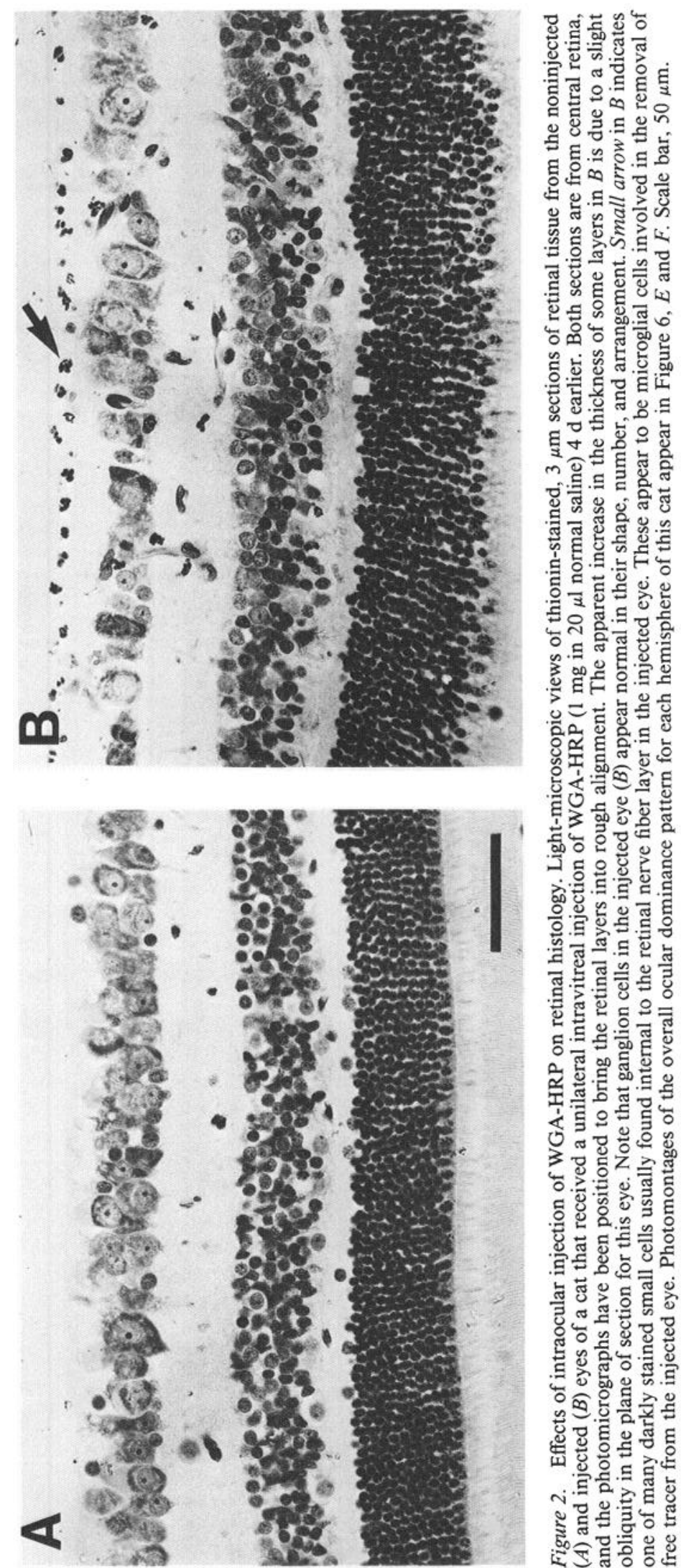



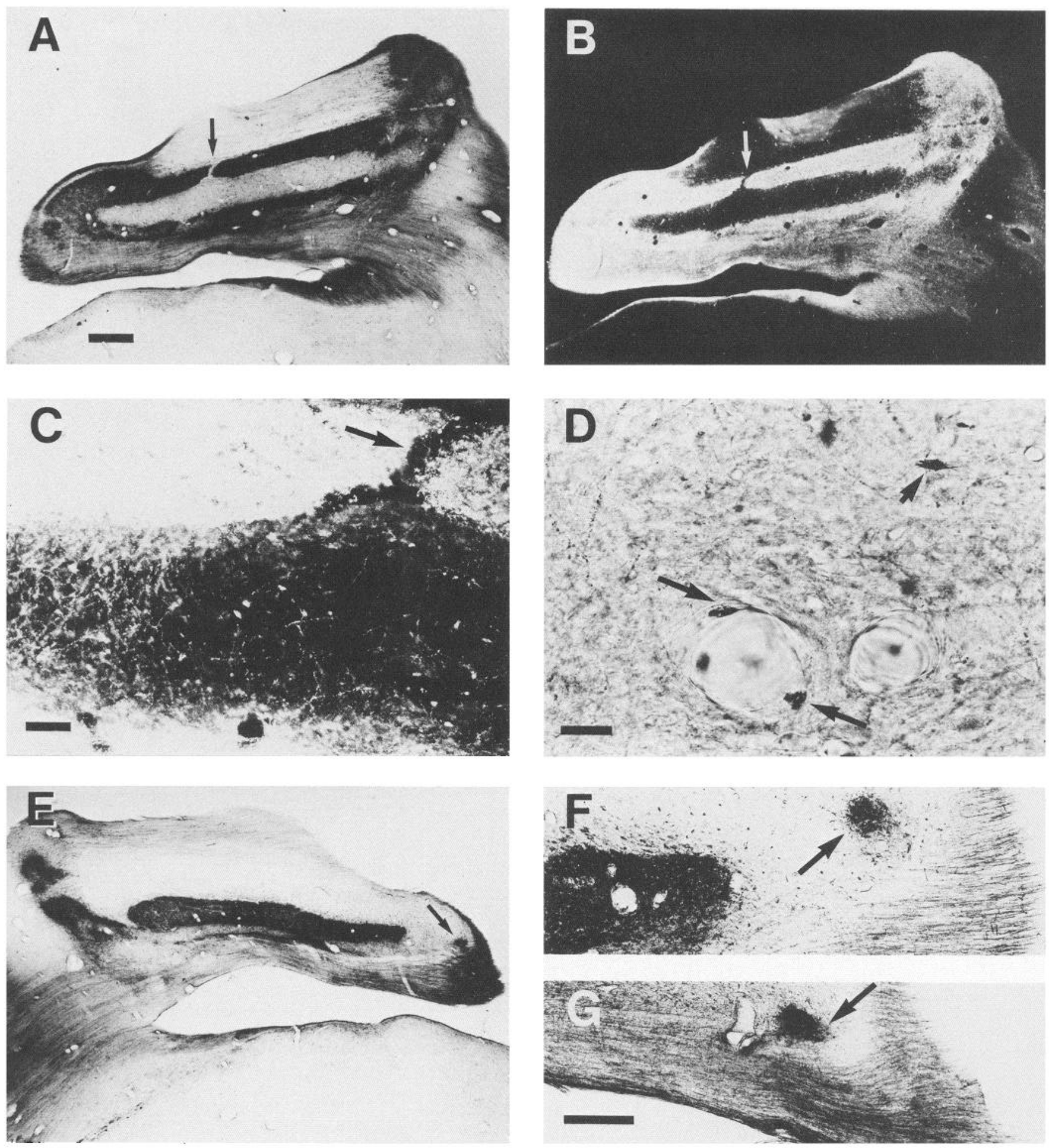

Figure 3. HRP labeling in the thalamus. Light- and dark-field views of the thalamus, demonstrating the apparent uniformity with which WGAHRP was taken up and transported from the injected eye. $A$ and $B$, Low-magnification bright- and dark-field views, respectively, of a single, HRPtested, $60 \mu \mathrm{m}$ coronal section from the left thalamus of a cat whose right eye was injected with WGA-HRP $4 \mathrm{~d}$ earlier. The arrows in $A-C$ indicate a sharp gap in the otherwise uniform labeling of lamina A that marks the representation of the optic disk for the contralateral (injected) eye. Scale bar in $A, 500 \mu \mathrm{m}$; panels $B$ and $E$ at the same scale. $C$, Higher-magnification view of a portion of $B$, indicating that most of the HRP-reaction product found in lamina Al contralateral to the injected eye appears to be confined to fibers of passage. Scale bar, $100 \mu \mathrm{m}$. $D$, Even higher magnification bright-field view confirms that some of the label present in contralateral lamina $\mathrm{Al}$ of this cat is also in endothelial cells (long arrows) and that some is artifact (short arrow). Scale bar, $25 \mu \mathrm{m}$. E , Labeling pattern ipsilateral to the injected eye in the same cat as in $A-D$ in a lowmagnification bright-field view of the right thalamus. Arrows in $E$, and in the higher-magnification view of the lateral portion of this same section $(F)$, indicate a region of anomalous uncrossed retinal input to lamina A first described by Polley and Guillery (1980). Arrow in $G$ indicates a similar region of uncrossed input to lateral lamina $\mathrm{A}$ in a second cat. Scale bar in $G, 200 \mu \mathrm{m} ; F$ shown at the same scale. 


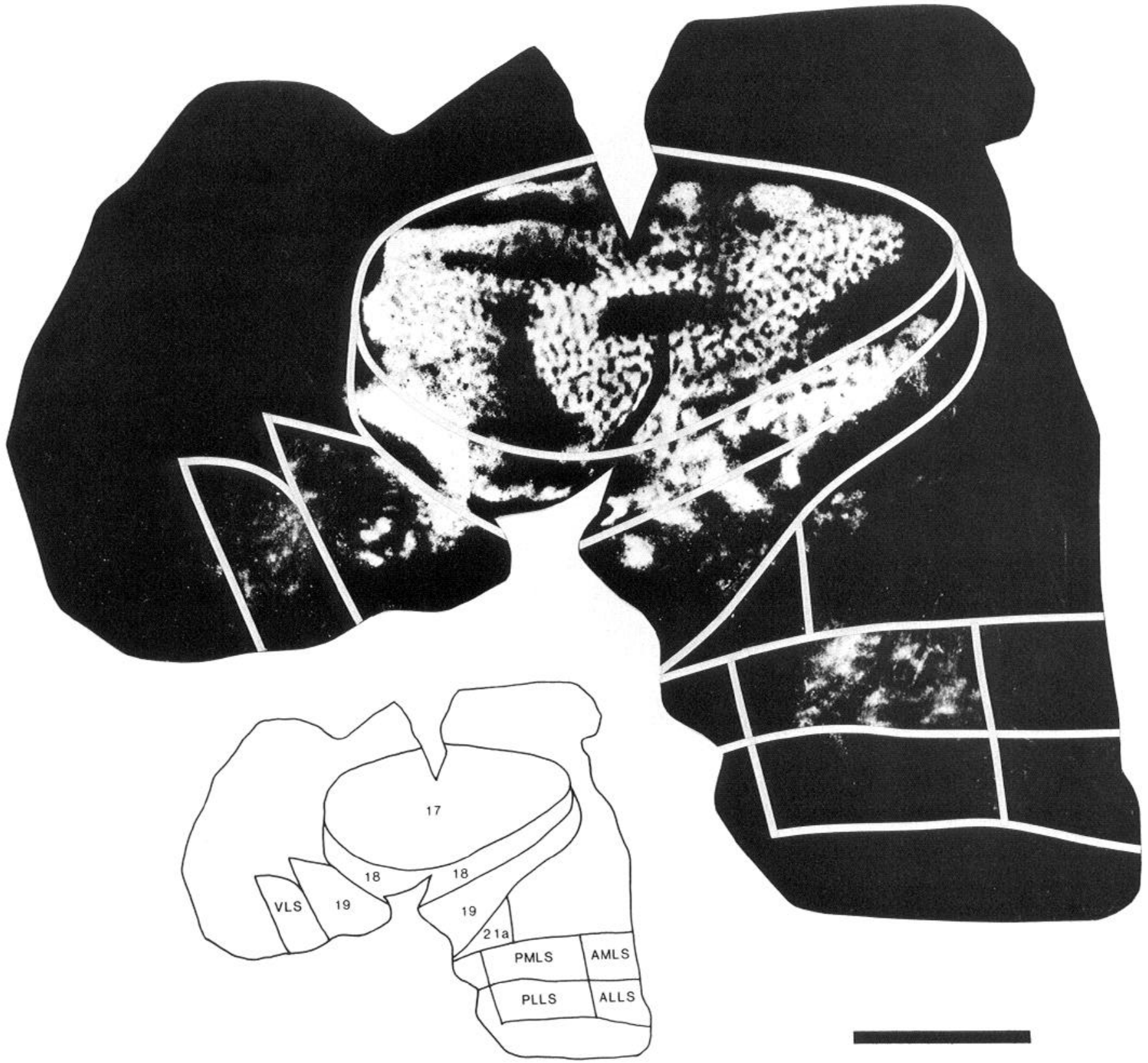

Figure 4. Transneuronal labeling pattern in posterior neocortex. Dark-field photograph of the overall distribution of transneuronally transported WGA-HRP in single section taken from a block of unfolded and flattened cortical tissue. Anterior is to the right, lateral is down. Labeled regions appear white, and white lines indicate approximate locations of cortical visual areas in the cat (see text and Fig. 1). A photomontage of the ocular dominance pattern in area 17 of this hemisphere appears in Figure $6 \mathrm{C}$. Same abbreviations and conventions as in Figure 1; scale bar, $1 \mathrm{~cm}$.

Figure 5. Transneuronal labeling pattern in areas 17 and 18. A, Dark-field photograph of a tangential section, demonstrating the proportion of the overall ocular dominance pattern in areas 17 and 18 that was often recovered from a single section. $B$, Photomontage that reconstructs the entire ocular dominance pattern in this hemisphere, which was ipsilateral to the injected eye. Five tangential sections were used to construct this photomontage. Solid white line, approximate location of the border of area 17; anterior is to the right; lateral is down. Scale bar, $5 \mathrm{~mm}$.

Figure 6. Overall pattern of ocular dominance bands. $A-F$, Photomontages reconstructing the ocular dominance patterns in both hemispheres of 3 cats. For each cat, the pattern contralateral to the injected eye is shown at the $\operatorname{top}(A, C$, and $D)$, and the pattern ipsilateral to the injected eye at the bottom $(B, D$, and $F)$. Note that to facilitate comparison, both hemispheres of each cat are oriented as if they were right hemispheres. Solid white lines, approximate location of the border of area 17; anterior is to the right; lateral is down. Small inset at bottom can be used to assess and compare the approximate locations of various retinotopic landmarks in these reconstructions of striate cortex, including the cortical representation of the optic disk $(O D)$, the center of the area centralis $(*)$, the horizontal $(H)$ and vertical $(V)$ meridians, and the central $10^{\circ}$ of the visual field. Scale bar, $5 \mathrm{~mm}$. 

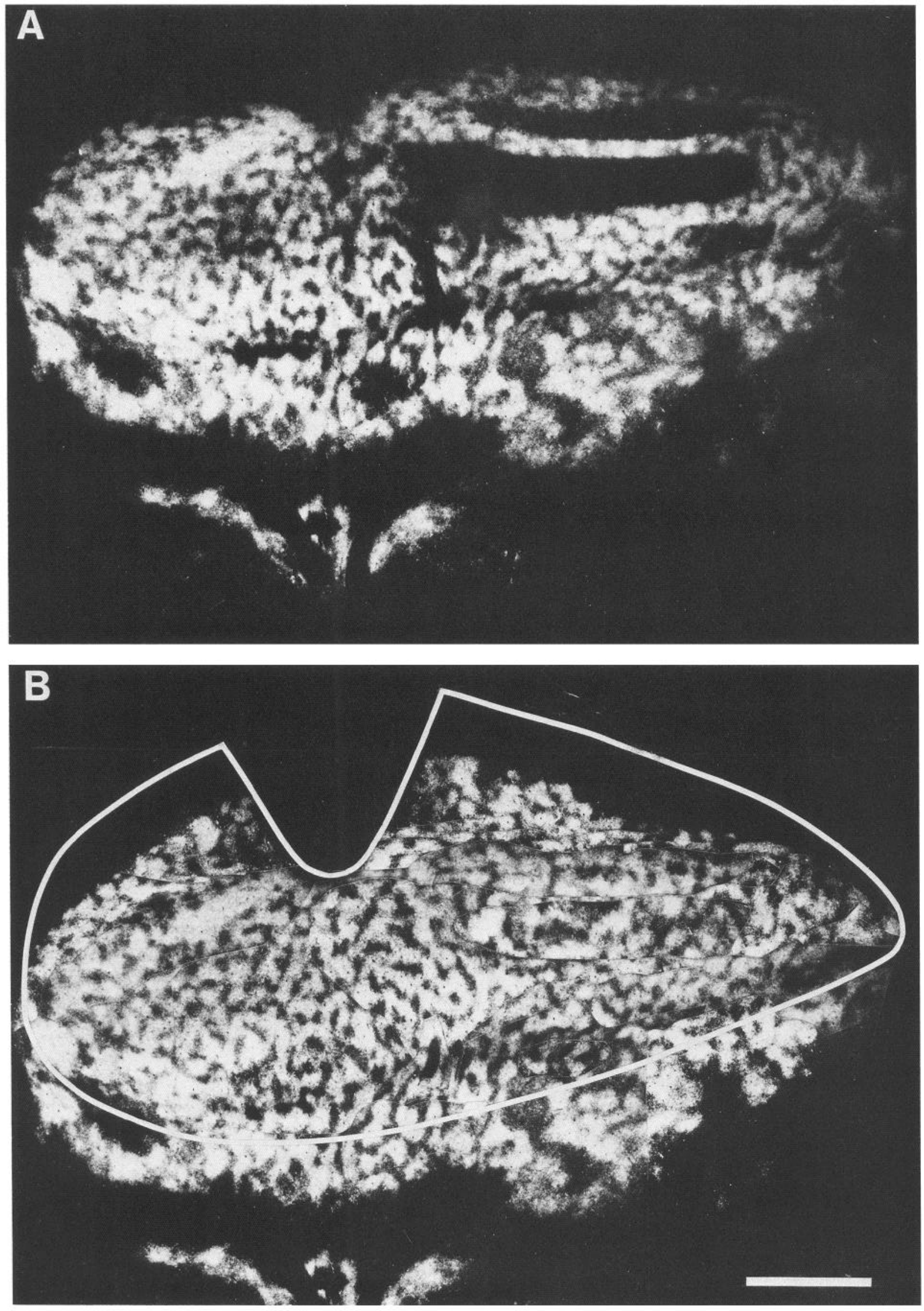

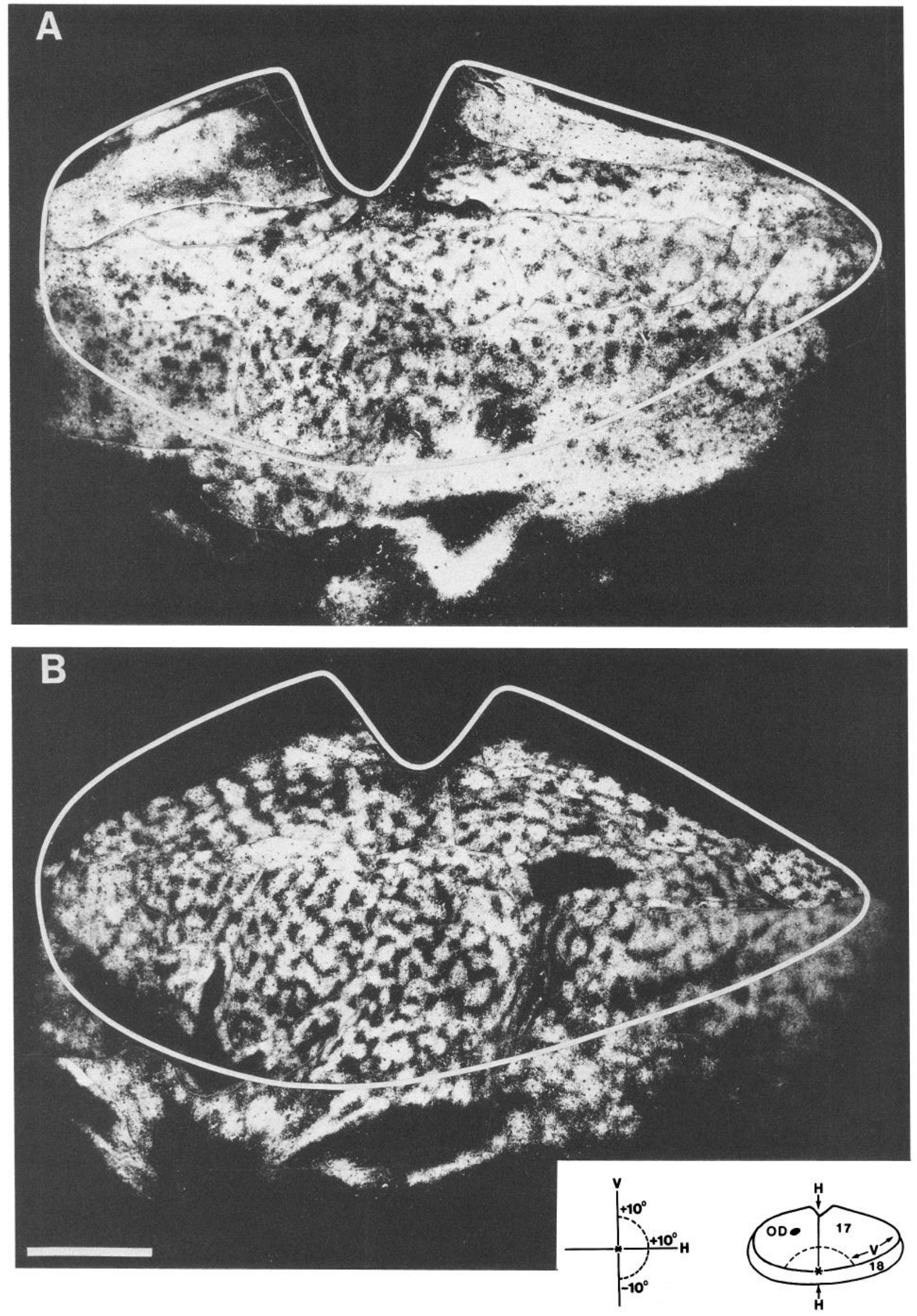

Figure 6. 

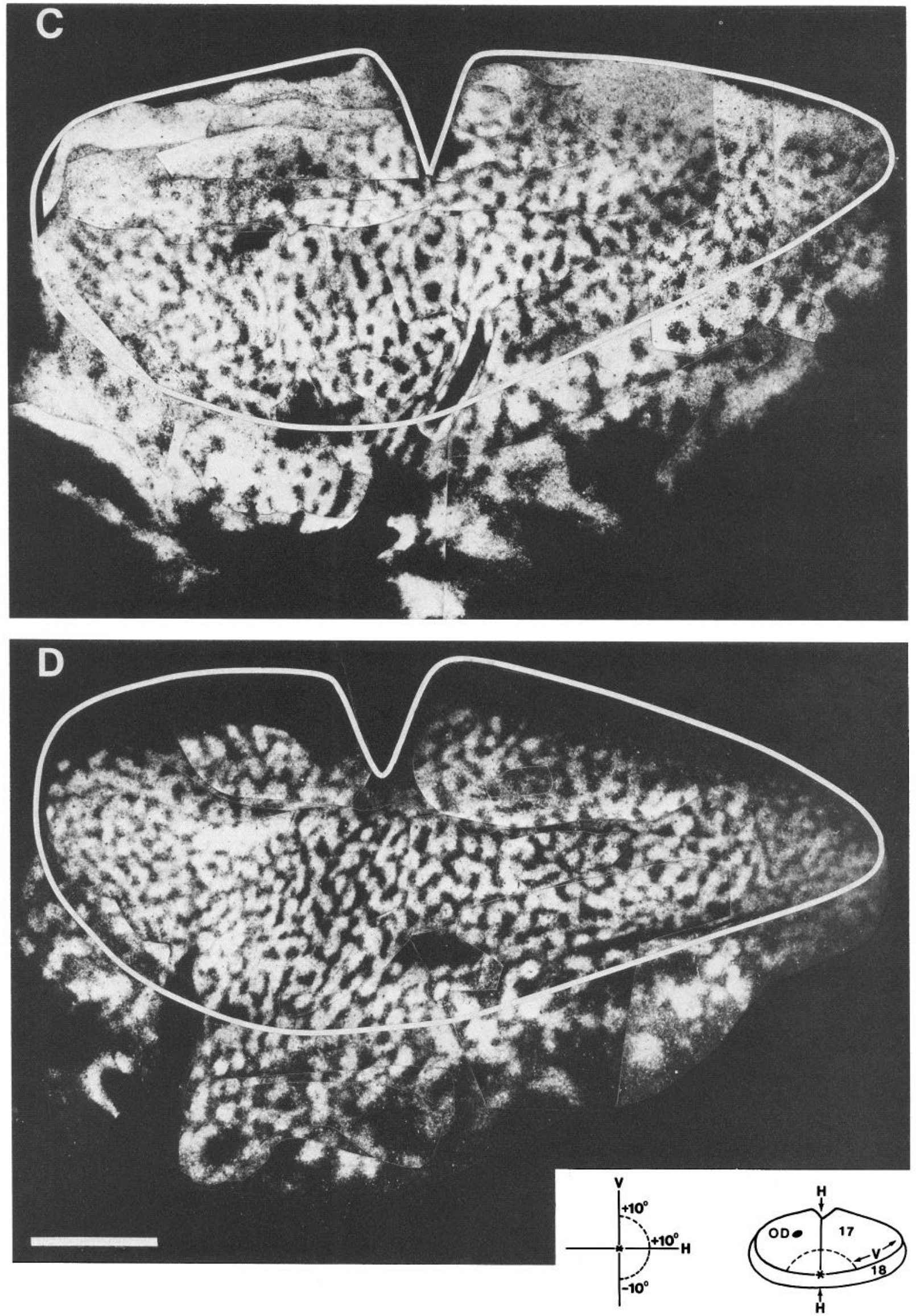

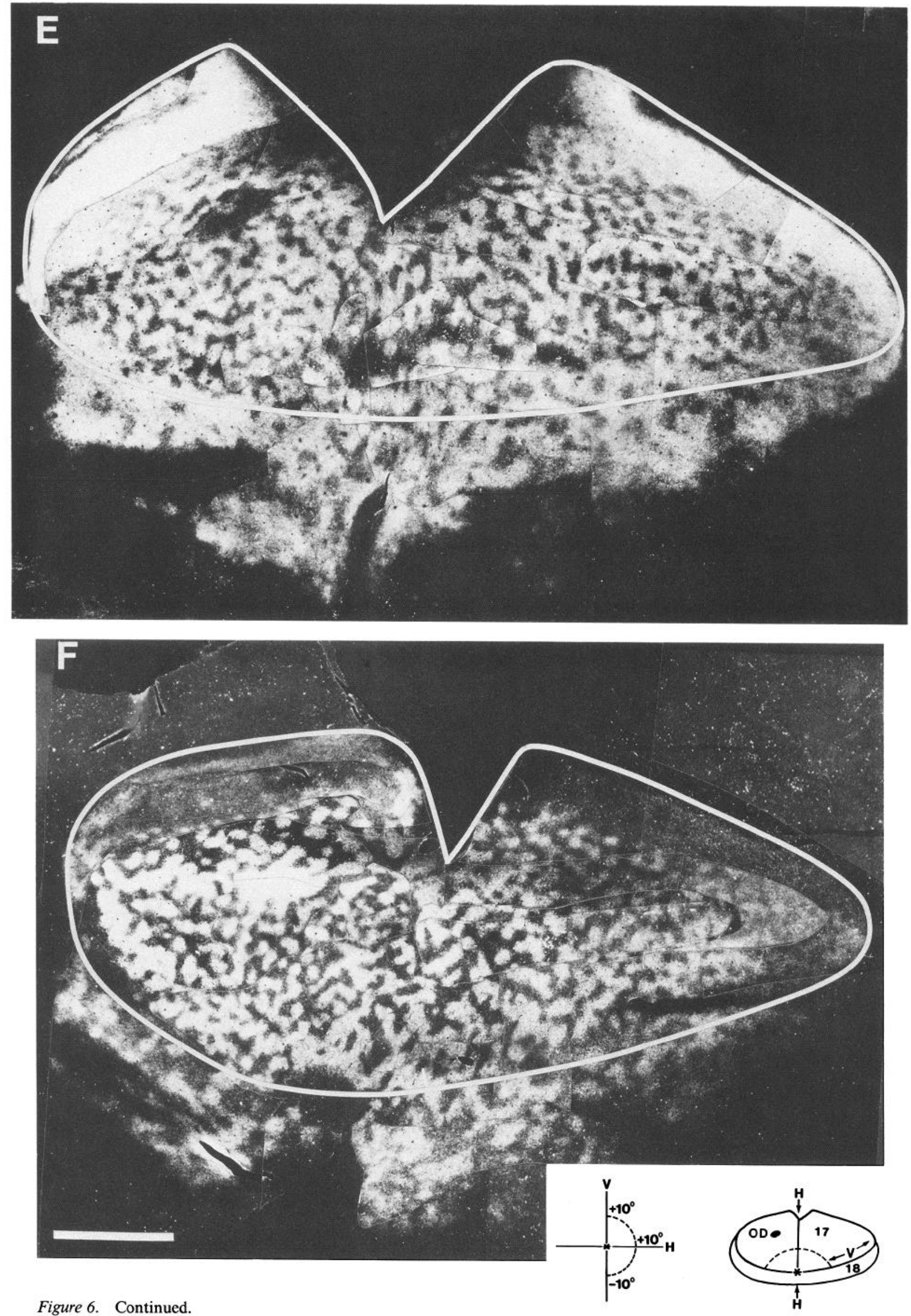
In the ipsilateral dLGN, laminae $\mathrm{Al}$ and $\mathrm{Cl}$ are heavily labeled, and the labeling in lamina $\mathrm{Al}$ is evenly distributed (Fig. $3 E$ ). Although we made no attempt to search for it systematically, in some cats we observed a small, well-circumscribed cluster of relatively dense terminal labeling within the monocular segment of lamina $A$ in the ipsilateral dLGN (arrow in Fig. $3 E-G)$. This labeling appears to correspond to the zone of anomalous uncrossed retinal input to the lateral portion of lamina $A$ that was first described by Polley and Guillery (1980). Dense labeling is also present in the appropriate regions of the ipsilateral MIN and GW.

\section{Pattern of labeling in the posterior neocortex}

Figure 4 displays a dark-field view of the overall distribution of transneuronally transported WGA-HRP in a single tangential section through the unfolded and flattened posterior neocortex contralateral to the injected eye. In this figure, labeled regions of the cortex appear white, and solid lines have been drawn to indicate the approximate locations of the borders of visual areas. Inspection of Figure 4 reveals a banded pattern of dense labeling that spreads across areas 17 and 18 . Some labeling is also present in area 19. In addition, weak labeling is found in the medial bank of the suprasylvian sulcus, in areas that appear to correspond to the ventral lateral and the posteromedial suprasylvian visual areas described by Palmer et al. (1978). This labeling in the suprasylvian sulcus tends to be rather patchy, and it is somewhat denser in the hemisphere contralateral to the injected eye. In the remainder of this paper, we will first analyze the pattern of labeling in cortical area 17 and then briefly comment on the pattern in area 18.

\section{Size of area 17}

As shown in Figure 4 (see also Fig. 6), unfolding and flattening the cortex reveals that the 2-dimensional shape of area 17 is ovate, with its narrower aspect oriented anteriorly (see also Olavarria and Van Sluyters, 1985). Examination of 8 hemispheres taken from 4 cats ( 10 mo.-2.5 yr) indicates that area 17 measures $35 \mathrm{~mm}$ anteroposteriorly (range, $32-38 \mathrm{~mm}$ ) and $16 \mathrm{~mm}$ mediolaterally (range, 15-16.5 $\mathrm{mm}$ ), giving it an average lengthto-width ratio of 2.2:1. In these same animals the average surface area of striate cortex is $399 \mathrm{~mm}^{2}$ (range, $358-428 \mathrm{~mm}^{2}$ ). This latter value is similar to the $332 \mathrm{~mm}^{2}$ we obtained from an earlier sample of 7 unfolded and flattened hemispheres from 6 cats whose ages ranged from 8 to $15 \mathrm{mo}$. (Olavarria and Van Sluyters, 1985) and to the 380 and $310 \mathrm{~mm}^{2}$ given in 2 previous reports (Tusa et al., 1978; Van Essen and Maunsell, 1980, respectively).

\section{Pattern of labeling in Area 17}

Ocular dominance bands. Figure $5 A$ shows a dark-field photomicrograph of a $50 \mu \mathrm{m}$ tangential section through areas 17 and 18 of the hemisphere ipsilateral to an injected eye. Much of the overall ocular dominance pattern in areas 17 and 18 is present in this one section. Features of the pattern that are repeated in successive sections make it relatively easy to align a series of tangential sections, thus facilitating the construction of photomontages that contain the complete pattern of ocular dominance bands. The photomontage in Figure $5 B$ was constructed using the section in Figure $5 A$ and portions of 5 additional sections.

Figure 6 shows photomontages we constructed for the contralateral and ipsilateral hemispheres of 3 cats. For ease of comparison, both hemispheres of each cat are oriented as if they were right hemispheres, and the approximate location of the boundary of area 17 is indicated by a solid line. For each pair of photomontages, the small diagram shown in the inset shows the approximate relationship between features of the retinotopic map in area 17 and the ocular dominance pattern in this area. This diagram - which indicates the approximate locations of the cortical representation of the optic disk (OD), the horizontal meridian $(\mathrm{H})$, the vertical meridian $(\mathrm{V})$, and the central $10^{\circ}$ of the visual field in area 17-is based loosely on the flattened map of cortical retinotopy presented by Tusa et al. (1978; see Fig. 6).

In all cats of this study, the pattern of WGA-HRP labeling in area 17 consists of a relatively continuous network of irregularly branching bands in both the ipsi- and contralateral hemispheres (Fig. 6). In both hemispheres, the spaces between ocular dominance bands contain label that is above background levels. (When this labeling is weak, it is often not visible in our photomicrographs since it tends to drop out during the photographic process.) In agreement with previous investigators (Shatz et al., 1977; Le Vay et al., 1978; Shatz and Stryker, 1978), we find that this interband labeling is more pronounced in the contralateral hemisphere (cf. Fig. 6, A, C, and $E$, with $B, D$, and $F$ ). In addition, the gaps between bands often appear to be more heavily labeled in cortical regions representing more peripheral aspects of the binocular portion of the visual field than they do in regions representing the central visual field. As a result of these 2 trends, ocular dominance bands are often least distinct in those portions of the contralateral hemisphere that receive projections from the peripheral retina and most distinct in the region of the ipsilateral hemisphere that receives projections from the area centralis.

When individual bands that make up the ocular dominance pattern are considered, it becomes apparent that their width fluctuates, giving them a distinctly beaded appearance. The beads of label within the bands appear to be roughly circular and similar in size. Measurements from both hemispheres of one cat (Fig. 6, $A, B$ ) indicate that the diameter of clearly recognizable beads $(n=253)$ averages $667 \mu \mathrm{m}(\mathrm{SD}=151 \mu \mathrm{m})$. Although the greater level of interband labeling in portions of the contralateral hemisphere makes it more difficult to measure bead diameter, the average size of easily recognized beads does not appear to differ between the 2 hemispheres (contralateral hemisphere: $676 \mu \mathrm{m}, \mathrm{SD}=148 \mu \mathrm{m}, n=123$; ipsilateral hemisphere: $653 \mu \mathrm{m}, \mathrm{SD}=152 \mu \mathrm{m}, n=130$ ).

Orientation of ocular dominance bands. Previous reports have suggested that ocular dominance bands in the cat tend to run mediolaterally, in a direction roughly orthogonal to the $17 / 18$ border (e.g., Shatz et al., 1977). However, examination of the labeling patterns in Figure 6 reveals that ocular dominance bands occur at all orientations, and in the hemispheres we studied there appears to be no overall tendency for bands to be oriented along a preferred axis.

Figure 7 illustrates the method we used to determine the degree to which ocular dominance bands tend to have a preferred orientation. We applied this analysis to the cortical region where the central $10^{\circ}$ of visual field are represented. This region opposes the border with area 18 and thus contains bands whose orientation has been reported to be biased. In addition, the labeling pattern in this region usually is not disturbed by the cuts we make in the process of unfolding and flattening the cortex. Because 4 of the 10 hemispheres we studied contain small defects in this region, they are not included in this analysis. 

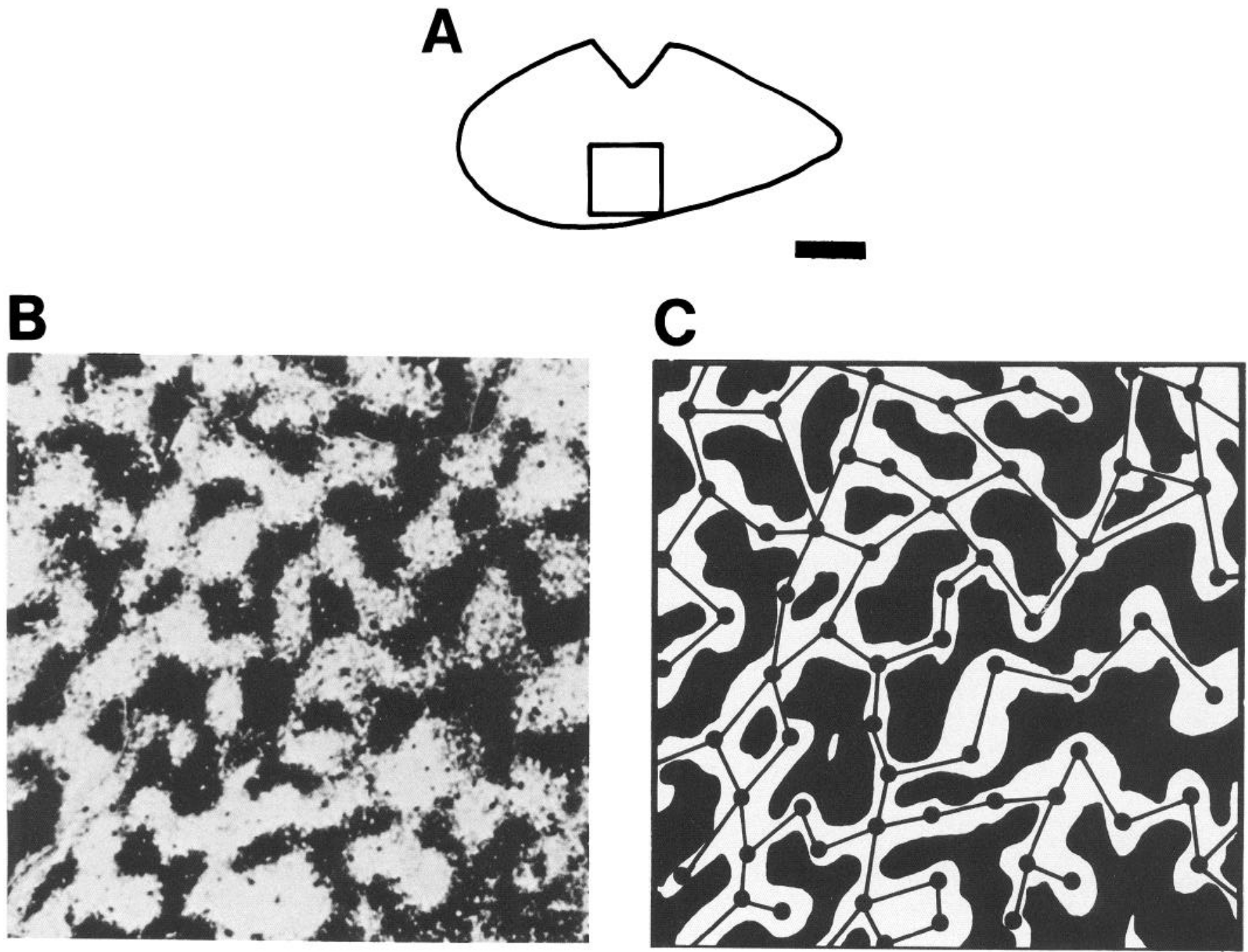

Figure 7. Analysis of the orientation preference of ocular dominance bands. A, Diagram indicating the location of the $6 \times 6 \mathrm{~mm}$ region of the photomontage shown in Figure $6 B$ in which the orientation preference of ocular dominance bands was sampled. In each hemisphere studied, this sampling region was oriented so that its lateral side was roughly parallel to the $17 / 18$ border. Scale bar, 6 mm. $B$, Enlarged dark-field photograph of the labeling pattern contained inside the sampling region shown in $A$. $C$, Diagram of labeling pattern shown in $B$, illustrating the placement of the dots within each of the beads of label and the lines that were drawn to connect dots representing neighboring beads of label that are linked to form an individual ocular dominance "band." The orientation of each of the lines in $C$ was measured using a digitizing tablet and a computer, and the resulting data are shown in Figure $8 B$. Note that the final placement of the dots and lines in $C$ is based on careful examination of the labeling pattern in several successive sections from this hemisphere. Scale bar, $1 \mathrm{~mm}$.

In the remaining hemispheres (Figs. $5 B$ and $6, A-D, F$ ), we analyzed the labeling pattern in a $6 \times 6 \mathrm{~mm}$ sampling region in the area centralis representation. Figure 7 shows the overall location of the sampling region for the hemisphere shown in Figure $6 B$, as well as an enlarged view of the labeling pattern contained in the sampling region.

In our initial attempt to encode the orientation of individual bands within a sampling region, we found it difficult to define the beginning and end of an individual band. However, the distinctly beaded nature of the labeling pattern suggested a possible solution to this problem. We found it relatively easy to position a dot at the center of each bead in the ocular dominance pattern for a given hemisphere and then to draw straight lines between pairs of dots representing neighboring beads that were linked together in the original pattern. Thus, for the purposes of the present analysis, each line segment that connects a pair of dots is defined as a single ocular dominance "band." Figure $7 C$ shows a drawing of the resulting array of bands for the labeling pattern in the sampling region shown in Figure $7 B$. A similar array was constructed for each of the remaining hemispheres, and a graphics pad and computer were used to digitize these arrays and sort the distribution of bands in each array into 9 orientation bins whose widths were set at $20^{\circ}$.

The results of this analysis are given in the histograms of Figure 8, which displays the number of bands that occurred at a given orientation for each of the 6 hemispheres analyzed. These histograms reveal that in some hemispheres ocular dominance bands appear to be distributed roughly equally across all orientations (e.g., Fig. $8 B$ ), while in others the distribution seems clearly biased (e.g., Fig. 8C). A $\chi^{2}$ statistical analysis was used 

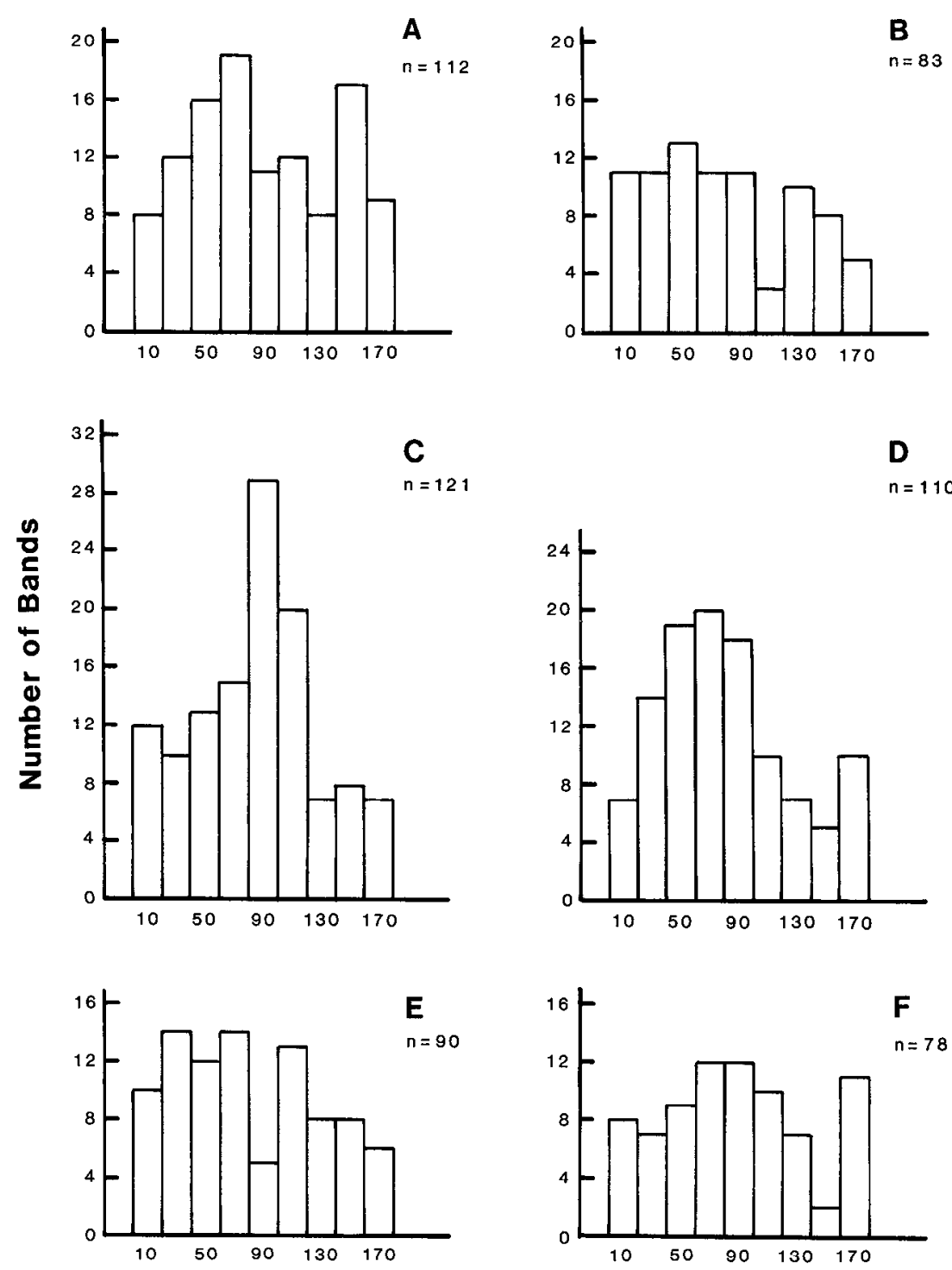

\section{Orientation (Degrees)}

Figure 8. Orientation preference of ocular dominance bands. The histograms display the results of the analysis of orientation preference illustrated by Figure 7 and described in the text. Each histogram indicates the number of bands (plotted on the abscissa) that occurred at a given orientation (plotted on the ordinate) in the sampling region for one hemisphere. Photographs of the overall ocular dominance patterns in the 6 hemispheres that were analyzed to produce the data shown in histograms $A-$ $F$ appear in Figures 5 and $6(8, A, B=$ $6, A, B ; 8, C, D=6, C, D ; 8, E, F=$ $6 F, 5 B)$. As shown in Figure 7, the sampling region for each hemisphere was arranged so that an orientation of $90^{\circ}$ was assigned to bands running roughly orthogonal to the $17 / 18$ border. to determine whether each of these histograms differed significantly from a random distribution (i.e., equal numbers of bands at all orientations). The results indicated that the histograms shown in Figure $8, A, B, E, F$, do not differ significantly from a random distribution $\left(\chi^{2}=10.46,9.28,9.40,9.23, d f=8, p>\right.$ 0.20 ), but that those shown in Figure $8, C$ and $D$, are significantly nonrandom $\left(\chi^{2}=30.81,21.24, p<0.01\right)$.

This analysis of our data demonstrates that ocular dominance bands in the area centralis region of striate cortex are not oriented along a preferred axis in all cats. On the other hand, in both hemispheres of 1 of the 4 cats studied, ocular dominance bands tended to be concentrated in the region of $70-110^{\circ}$ (see Fig. 8, $C$ and $D$ ), or roughly orthogonal to the $17 / 18$ border. Thus, our data indicate that ocular dominance bands can be oriented nonrandomly in some cats and that in these cats the preferred orientation can be roughly orthogonal to the $17 / 18$ border.

Optic disk and monocular segment. There are 2 regions in area 17 where inputs are received from only one eye-the representation of the optic disk and the representation of the mon- ocular segment of the visual field. The optic disk lies in the lower nasal portion of the retina (azimuth $=14.6^{\circ}$, elevation $=$ $-6.5^{\circ}$; Bishop et al., 1962) and is slightly elliptical in shapc $(1.07 \times 0.97 \mathrm{~mm})$, with its long axis pointing towards the area centralis (Vakkur et al., 1963). In the dLGN, the representation of the optic disk appears as a cell-sparse region in lamina $A$ (Guillery and Kaas, 1971) and as a gap in the otherwise uniform pattern of WGA-HRP transported from the retina to this lamina (e.g., see Fig. 3). In our HRP-tested tangential sections through flattened cortical tissue, the representation of the optic disk is also visible in the posteromedial portion of cat striate cortex. In the 4 cats whose data are shown in Figures 5 and 6 , the representation appears as a relatively large elongated area that is labeled in the hemisphere ipsilateral to the injected eye (Figs. 5 and $6, B, D, F)$ and unlabeled in the contralateral hemisphere (Fig. 6, $A, C, E$ ). Measurement of these areas indicated that the optic disk representation was about $2 \times 1 \mathrm{~mm}$.

As Figures 5 and 6 indicate, the cortical representation of the optic disk is elongated in a direction roughly parallel to the border between the monocular and binocular segments of striate 
cortex. Thus, it would seem to be a general feature of cat visual cortex that the optic disk representation is elongated in a direction parallel to the representation of the vertical meridian and perpendicular to that of the horizontal meridian. Finally, inspection of Figures 5 and 6 reveals that the arrangement of ocular dominance bands bears no special relationship to the representation of the optic disk, contrary to a previous report that they are organized radially with respect to the disk (Silverman et al., 1982).

The portion of the temporal retina that subserves the monocular segment of the visual field projects to the lateral portion of lamina $A$ in the dLGN (Guillery and Kaas, 1971; but see Polley and Guillery, 1980, and our Fig. 2). In striate cortex the representation of the monocular segment lies in the depths of the splenial sulcus (e.g., Talbot and Marshall, 1941; Woolsey, 1971). In our tangentially sectioned material, this region appears as a crescent-shaped zone that is homogeneously labeled in the hemisphere contralateral to the injected eye (Fig 6, $A, C$, and $E$ ), and relatively unlabeled in the ipsilateral hemisphere (Fig. $6, B, D$, and $F$ ). We find that the cortical representation of the monocular segment measures about $2 \mathrm{~mm}$ at its widest and occupies approximately $12 \%$ of the total area of the striate cortex.

\section{Pattern of labeling in area 18}

The photomontages in Figures 5 and 6 reveal several features of the ocular dominance bands in area 18. In the contralateral hemisphere, the bands often appear more barlike than those in area 17 , and they seem more likely to be oriented roughly orthogonal to the $17 / 18$ border. As a result, they frequently appear to bridge the body of area 18 (e.g., see Fig. 6C). In the contralateral hemisphere, the bands in area 18 clearly appear to be broader than those in area 17 (see Shatz et al., 1977), and "widths" (measurements of labeled areas taken parallel to the $17 / 18$ border) of $1 \mathrm{~mm}$ or more are not uncommon. In the ipsilateral hemisphere, the bands in area 18 are more beaded, less likely to be orthogonal to the $17 / 18$ border, and on the whole somewhat smaller than in the contralateral hemisphere, so that here they are more like the bands in area 17. However, even in this hemisphere it is possible to find bands in area 18 whose size exceeds the largest of those in area 17.

\section{Discussion}

In this study, the complete pattern of ocular dominance bands in 5 adult cats was reconstructed from tangential sections taken through the unfolded and flattened cortex. Since earlier reconstructions of the ocular dominance pattern in the cat are incomplete, our findings extend previous data in several ways. In the discussion that follows, we comment first on several methodological considerations that are relevant to the study of ocular dominance bands. Next, we compare our results to previous data on ocular dominance bands in the cat and monkey. Finally, we discuss our data in the context of theoretical considerations about cortical organization and ocular dominance column formation.

\section{Methodological considerations}

Suitability of our technique for reconstructing ocular dominance patterns. In previous investigations, conventional serial reconstruction procedures were used to reconstruct portions of the tangential array of ocular dominance bands in the cat (Shatz et al., 1977; LeVay et al., 1978) and monkey (LeVay et al., 1975). An alternative procedure was recently described by LeVay et al. (1985), who used both manual (Van Essen and Maunsell, 1980) and computerized techniques to reconstruct the complete ocular dominance pattern in the monkey from a series of sections taken through the intact brain. However, in each of these previous studies many sections were needed to reproduce an ocular dominance pattern, and this makes it difficult to achieve an accurate reconstruction. In the present study, we unfolded and flattened the cortex prior to sectioning it tangentially (Olavarria and Van Sluyters, 1983, 1985). With this more direct approach, only 5 sections are usually required to reconstruct an entire ocular dominance pattern. Since far fewer sections must be analyzed, this approach can potentially yield more accurate reconstructions.

In the present study, we did not measure tissue distortion. While any histological procedure alters cortical tissue, several factors lead us to believe that the distortion caused by our techniques does not seriously affect our ocular dominance data. First of all, our fixations resulted in firm tissue that was resilient to the pressure applied for flattening. Second, in an earlier description of our technique for unfolding and flattening the cortex, Olavarria and Van Sluyters (1985) assessed the integrity of flattened tissue and found no gross distortions of cortical cytoarchitecture. Finally, to minimize variability between animals, we were consistent in our treatment of each hemisphere, being careful to use the same fixation and tissue processing parameters and to make the cuts in the margin of the tissue block in the same locations.

Uniformity of labeling. The average density of labeling was not always uniform across area 17 in our reconstructed ocular dominance patterns. For example, it was often slightly reduced in the region of the area centralis projection (e.g., Fig. 6, $A$ and $D$ ), a finding also reported by LeVay et al. (1978). It seems unlikely that this reduction could be caused by input derived from central retinal ganglion cells spreading over a greater region of the cortex than that from peripheral ganglion cells, since the cortical magnification factor in the cat appears to parallel closely the distribution of ganglion cell density across the retina (e.g., see Tusa et al., 1978). Interestingly, this does not seem to be the case in the monkey, where enhancement of the cortical magnification factor in the foveal region of striate cortex (Rolls and Cowey, 1970; Malpeli and Baker, 1975; Van Essen et al., 1984) may be the basis for the reduced labeling that is found in this region (e.g., LeVay et al., 1985).

Another possible source of unevenness in cortical labeling patterns is nonuniform uptake of label across the retina of the injected eye. There are several factors that could lead to nonuniform uptake of WGA-HRP in the injected eye. First, the eye might suffer local damage during the injection procedure, although comparison of retinal tissue from the injected and noninjected eyes of our cats suggests that this was not a factor in the present study (e.g., see Fig. 2). Second, since ganglion cells are arrayed in multiple layers in cat area centralis (e.g., see Fig. 2 ), underlying cells in this part of the retina may be screened from WGA-HRP injected into the vitreous. This could be the basis for our finding that the density of labeling tended to be somewhat reduced in the portion of the cortex representing the central retina. Finally, if WGA-HRP tends to settle to the bottom of the injected eye, the inferior retina may be exposed to higher concentrations of label than the superior retina. Since the inferior retina projects to the posterior portion of striate cortex, 
this latter factor could explain the relatively reduced labeling we often observed in the anterior portion of area 17.

Spillover and the monocular segment. Although it is not critical for observations about the pattern of ocular dominance bands, we feel it is worthwhile commenting on the issue of "spillover." A disadvantage in using ${ }^{3} \mathrm{H}$-proline to label ocular dominance bands is that this tracer may diffuse out of axons (e.g., Grafstein and Laureno, 1973; Specht and Grafstein, 1977). This complicates the interpretation of cortical labeling patterns, since label injected into one eye may spill over into the inappropriate dLGN lamina and allow cells innervated by the noninjected eye to transport label to cortex (Shatz et al., 1977; LeVay et al., 1978). The pattern of labeling we see in the dLGN suggests that spillover does not occur with WGA-HRP. Dark-field views of lamina $\mathrm{Al}$ in the dLGN contralateral to an eye injection indicate that label is probably confined to fibers of passage (see Fig. 3). Additionally, the area corresponding to the optic disk in lamina $\mathrm{A}$ (arrows in Fig. 3, A-C) was clear, suggesting no lateral diffusion of WGA-HRP. This indirect evidence-together with reports that in mature mammals very little, if any, WGA (Ruda and Coulter, 1982; Spencer et al., 1982) or WGA-HRP (Gerfen et al., 1982; Itaya and Van Hoesen, 1982; Itaya et al., 1984) diffuses out of axons or away from sites of transsynaptic transfer-strongly suggests that spillover in the dLGN does not contribute significantly to our cortical labeling patterns.

Another way to assess spillover has been to look for label in the upper and posterior banks of the splenial sulcus of the hemisphere ipsilateral to an eye injection, where the contralateral eye's monocular segment is represented (LeVay et al., 1978). Although we feel there is little or no spillover of WGA-HRP in the dLGN, we do find label at above background levels in this region of the cortex. There are 2 other possible sources for this label-endogenous peroxidative activity or real input.

When we used our TMB histochemical procedure to react control sections from a cat that had not received an intraocular injection of WGA-HRP, we found that both the monocular and binocular portions of area 17 were filled in with a low level of rcaction product comparable to that seen in the monocular segment representation of the ipsilateral hemispheres of cats that had been given an eye injection. Thus, area 17 appears to have a higher level of endogenous peroxidative activity than the immediately surrounding areas of the cortex. It is also possible that some input from the ipsilateral eye reaches the monocular segment of area 17 on the same side of the brain. In cats for which we saved extensive dLGN series, we see labeled terminal fields embedded in the monocular segment of lamina $\mathrm{A}$ in the dLGN ipsilateral to the injected eye (see Fig. 3 and Polley and Guillery, 1980). To our knowledge, the cortical destinations of the axons of the dLGN cells that receive this anomalous uncrossed retinal input are unknown. However, if these axons follow their neighbors into the monocular segment of area 17 , they could be another source of the low level of reaction product that we see in this region of the cortex following injection of the ipsilatcral cyc.

\section{Previous studies in the cat}

Ocular dominance bands in area 17. In agreement with previous investigators (Shatz et al., 1977; LeVay et al., 1978), we observe that the ocular dominance pattern in cat striate cortex is composed of a relatively continuous system of irregularly branching bands in the hemispheres both contralateral and ipsilateral to the injected eye. In addition, we find that a salient feature of the ocular dominance pattern is the fluctuation in the width of individual bands, which gives them a distinctly beaded appearance. Although the beaded nature of the bands makes it difficult to measure their width, we found that individual beads of label were fairly consistent in size, averaging about $670 \mu \mathrm{m}$ in diameter. This value is similar to that given by Shatz et al. (1977), who reported that discrete patches of ${ }^{3} \mathrm{H}$-proline label in frontal sections through layer IV were about $500 \mu \mathrm{m}$ wide.

It has also been reported that the ocular dominance bands run approximately orthogonal to the $17 / 18$ border in the cat (Shatz et al., 1977). Our analysis of a region of the ocular dominance pattern shows that for most hemispheres there is no bias in the distribution of band orientations. On the other hand, we did find a bias in both hemispheres of one cat, in which bands tended to occur more often at orientations roughly orthogonal to the $17 / 18$ border. A larger sample of cats must be studied before conclusions can be drawn about the significance of this finding. In addition, other forms of analysis could be used to assess the orientation bias of bands, such as one based on the total length of bands at each orientation, or spectral analysis of the ocular dominance pattern. However, it seems unlikely that the results obtained from such efforts would differ significantly from those reported here, since a simple visual inspection of our reconstructed ocular dominance patterns is sufficient to reveal that they lack a strong orientation bias.

Comparison of contralateral and ipsilateral hemispheres. Both LeVay et al. (1978) and Shatz and Stryker (1978) observed that densely labeled patches in layer IV seemed to occupy a larger fraction of cortical territory in the contralateral than in the ipsilateral hemisphere. Shatz and Stryker traced densely labeled patches in high-contrast enlargements of autoradiographs from one normal cat and confirmed this impression. We undertook measurements similar to those of Shatz and Stryker, tracing densely labeled regions in a series of prints of the ocular dominance patterns in 5 cats. In agreement with Shatz and Stryker, we find that the contralateral hemisphere is more filled in with densely labeled regions than the ipsilateral hemisphere. On the other hand, this seems to be the case only in regions of the cortex where peripheral fields are represented; in our ocular dominance patterns the size of the bands in the area centralis projection area does not appear to differ between hemispheres. However, given the difficulties of standardizing the photographic process, future efforts to assess the size of ocular dominance bands should involve the use of image-processing techniques to analyze HRPlabeled sections.

Comparisons with physiological data. The distribution of labeling we obtain correlates with previously reported physiological data. For example, Albus (1975) determined the ocular dominance of cells in area 17 by sampling along tangential penetrations through the posterolateral gyrus. He found that the proportion of monocularly driven cells was high in all cortical layers in the projection field of the area centralis (perhaps due in part to an overrepresentation of simple cells in his sample) and that the proportion of monocular cclls dccrcased with increasing eccentricity. This result, although controversial (e.g., see Berman et al., 1982), correlates well with our present anatomical findings and with the data of Tieman and Tumosa (1983), who used ${ }^{14} \mathrm{C}$-2-deoxyglucose as a marker for ocular dominance bands. Each of these neuroanatomical approaches indicates that bands are most distinct in the central fields of both hemispheres, suggesting that there is less binocular overlap in this region. Albus also found that the physiological domi- 
nance of the contralateral eye observed by previous investigators (Hubel and Wiesel, 1962; Blakemore and Pettigrew, 1970) was obvious only in the paracentral projection area. Similarly, Berman et al. (1982) reported that the strongest physiological dominance of the contralateral eye occurs for peripheral fields. Although our data suggest that the contralateral hemisphere is more filled in with label than the ipsilateral hemisphere in regions of peripheral field representation, it is not clear that these modest anatomical differences can account for the physiological biases previously reported.

Ocular dominance bands in area 18. In the present experiment, and in related previous studies (e.g., Shatz et al., 1977; Tieman and Tumosa, 1983), the bands in area 18 often appear larger than those in area 17, especially in the contralateral hemisphere. Area 18 is known to receive a very strong $\mathrm{Y}$ cell projection arising from the dLGN A laminae, lamina $C$, and the MIN (e.g., Stone and Dreher, 1973; Humphrey et al., 1985). The cells projecting to area 18 are on the whole larger than those projecting to area 17 (e.g., Hollander and Vanegas, 1977), and the axon terminal fields of $Y$ cells that project to area 18 are larger than those of cells that project to area 17 (Humphrey et al., 1985). These factors may underlie the difference in band size between areas 17 and 18 . Judging from the labeling patterns in the hemisphere contralateral to the injected eye, where the patches of label in area 18 frequently are more barlike, the individual ocular dominance bands running in layer IV often appear to be oriented roughly perpendicular to the $17 / 18$ and $18 / 19$ borders.

\section{Comparison of cat and monkey}

Comparison of our data with those from a recent study demonstrating the complete ocular dominance pattern in layer IV of macaque monkey striate cortex (LeVay et al., 1985) reveals that, in general, the pattern is much more regular in the monkey. For example, the width of individual bands seems to fluctuate less in the monkey, so that the ocular dominance pattern is less beaded in appearance than in the cat. Additionally, ocular dominance bands change orientation less frequently in the monkey, adopting the form of parallel stripes. Finally, bands in monkey cortex are oriented orthogonal to the V1/V2 border with a consistency that is strikingly different from the cat.

Our data indicate that the 2-dimensional shape of area 17 in the cat is ovate, with a length-to-width ratio of around 2.2:1 (see also Olavarria and Van Sluyters, 1985). LeVay et al.'s (1985) reconstructions of area 17 from one hemisphere reveal that monkey striate cortex is similarly shaped, and our measurements of their reconstructions (see their fig. 6) indicate that its length-to-width ratio (about 2.4:1) is also similar to that in the cat.

It is interesting to consider what might be responsible for the greater irregularity of the ocular dominance pattern in the cat compared with that in the monkey. One possible clue comes from differences in the way the visual hemifield is represented within striate cortex in these 2 species. Although, as pointed out above, the overall shape of area 17 is remarkably similar in these 2 species, in the monkey the representation of the horizontal meridian of the visual field runs approximately parallel to the long axis of the striate cortex, while in the cat it runs roughly parallel to the short axis. Thus, with respect to the ovate shape of primary visual cortex, the map of the visual hemifield in the cat is oriented orthogonally to that in the monkey. In the argument that follows, we suggest that this $90^{\circ}$ difference in the orientation of the map of the visual field may explain why the ocular dominance pattern in the cat is more irregular than that in the monkey.

The partially nonoverlapping nature of the geniculocortical projection to layer IV results in the binocular portion of the visual hemifield being mapped approximately twice within the striate cortex of both the cat and monkey. In each of these animals, the binocular portion of the visual hemifield includes approximately $55^{\circ}$ of the horizontal meridian and subtends about twice this angle at its maximum vertical extent, yielding a vertical-to-horizontal ratio of about $2: 1$. This ratio is similar to the length-to-width ratio of the striate cortex in both species. However, as pointed out above, in the monkey the retinotopic map is arranged in such a way that the short axis of the visual hemifield (i.e., the horizontal meridian) is mapped along the long axis of the striate cortex. Thus, in the monkey the retinotopic map has to expand considerably along the representation of the horizontal meridian of the visual hemifield in order to fit into the ovate shape of area 17. As LeVay et al. (1985) have recently discussed, given this situation the simplest way for the monkey brain to include 2 representations of the visual hemifield within area 17 is to slice the field into vertical strips and then to interdigitate strips for the right and left eyes. Furthermore, as these authors point out, as long as the resulting ocular dominance strips are arrayed orthogonal to the axis along which the visual field map is expanded (which in the monkey is the horizontal meridian), the amount of anisotropic stretching of the visual map will be minimized.

The above argument, which provides an explanation for the strong tendency for ocular dominance bands to be oriented perpendicular to the $17 / 18$ border in the macaque, also can be applied to the cat. In its general form, this argument implies that the pattern of ocular dominance bands is constrained by the fact that, in order to minimize anisotropy in the retinotropic map, the bands must run at right angles to the axis along which the visual map is expanded (LeVay et al., 1985). In the cat, where the horizontal meridian is mapped along the short axis of the striate cortex, the elliptical shape of the binocular hemifield fits the ovate shape of the striate cortex much better than in the monkey, where the retinotopic map is rotated by $90^{\circ}$. As a result, in the cat the visual map need not expand in any particular direction to fit the shape of area 17. Indeed, in order to fit 2 representations of the visual hemifield into area 17 , while at the same time minimizing anisotropic stretching of the visual map, ocular dominance bands would have to be arranged randomly in cat striate cortex. Thus, this line of reasoning leads to the prediction that there should be no overall tendency for ocular dominance bands to adopt a preferred orientation in cat striate cortex.

Our data indicate that this is, in fact, the case in most cats, although in both hemispheres of one animal we did find a slight tendency for ocular dominance bands in area 17 to be oriented perpendicular to the $17 / 18$ border. One possible explanation for a subtle bias in the distribution of band orientations in the cat is that the ratio of the length to the width of the striate cortex (2.2:1) may be somewhat greater than the ratio of the vertical to the horizontal extent of the binocular hemifield in this animal (2:1), creating a slight need to expand the visual map preferentially along the long axis of the striate cortex. Interestingly, this same reasoning could explain our finding that the cortical representation of the optic disk in the cat tends to be elongated in a direction roughly parallel to the long axis of the striate 
cortex. On the other hand, it is important to point out that other factors, such as local anisotropies in the visual map and variations in the actual dimensions of the optic disk from eye to eye, could also play a role in determining the way in which visual space is represented in layer IV of cat striate cortex.

It is intcresting to speculate on the significance of the beaded nature of the ocular dominance bands in the cat. For instance, the arrangement of these beads may provide an insight into the overall functional organization of cat striate cortex. If this area consists of a 2-dimensional array of "hypercolumns" or "modules" (e.g., Hubel and Wiesel, 1977; Hubel et al., 1978; Livingston and Hubel, 1984), then the spacing of the beads across striate cortex should reflect the density of these functional subunits. Interestingly, in the monkey the width of individual ocular dominance bands also tends to fluctuate periodically (e.g., see LeVay et al., 1985), although beads are much less obvious in this species than in the cat. This difference in the appearance of ocular dominance bands may reflect dissimilarities in the basic architecture of the functional subunits of cat and primate striate cortex. It also may offer clues to the rules governing the formation of ocular dominance bands during development.

This difference in the bcadedncss of ocular dominance bands is paralleled by a difference in the way the developing pattern of geniculocortical projections in these 2 animals is affected by exposure to long-term monocular deprivation. In the macaque, deprived-eye input to cortical layer IV takes the form of thin continuous stripes (e.g., Hubel et al., 1977; LeVay et al., 1980), whereas our preliminary findings indicate that in the cat the ocular dominance pattern for the deprived eye consists of a fairly regular array of isolated beads of label in the binocular portion of area 17 (Anderson et al., 1983; see also Plate 2, Shatz and Stryker, 1978). The discrete nature of these patches of label we observe in monocularly deprived cats makes it easier to specify their locations unambiguously. If, as we suspect, these patches actually correspond to the residual "cores" of the deprived eye's beads of cortical input, then in future studies quantitative analysis of their spatial array may shed further light on the modular organization of cat striate cortex.

\section{References}

Albus, K. (1975) Predominance of monocularly driven cells in the projection area of the central visual field in cat's striate cortex. Brain Res. 89: 341-347.

Anderson, P. A., J. Olavarria, and R. C. Van Sluyters (1983) The pattern of ocular dominance columns in areas 17 and 18 of normal and visually deprived cats as revealed in tangential sections of the unfolded cortex. Soc. Neurosci. Abstr. 9: 910.

Berman, N., B. R. Payne, D. R. Labar, and E. H. Murphy (1982) Functional organization of neurons in cat striate cortex: Variations in ocular dominance and receptive-field type with cortical laminae and location in visual field. J. Neurophysiol. 48: 1362 1377.

Bishop, P. O., W. Kozak, and G. J. Vakkur (1962) Some quantitative aspects of the cat's eye: Axis and plane of reference, visual field coordinates and optics. J. Physiol. (Lond.) 163: 466-502.

Blakemore, C., and J. D. Pettigrew (1970) Eye dominance in the visual cortex. Nature 225: 426-429.

Gerfen, C. R., D. D. M. O'Leary, and W. M. Cowan (1982) A note on the transneuronal transport of wheat germ agglutinin-conjugated horseradish peroxidase in the avian and rodent visual system. Exp. Brain Res. 48: 443-448.

Grafstein, B., and R. Laureno (1973) Transport of radioactivity from eye to visual cortex in the mouse. Exp. Neurol. 39: 44-57.

Guillery, R. W., and J. H. Kaas (1971) A study of normal and congenitally abnormal retinogeniculate projections in cats. J. Comp. Neurol. 143: 73-100.
Guillery, R. W., E. E. Geisert, E. H. Polley, and C. A. Mason (1980) An analysis of the retinal afferents to the cat's medial interlaminar nucleus and to its rostral thalamic extension, the "geniculate wing." J. Comp. Neurol. 194: 117-142.

Hayhow, W. R. (1958) The cytoarchitecture of the lateral geniculate body in the cat in relation to the distribution of crossed and uncrossed optic fibers. J. Comp. Ncurol. 110: 1-64.

Hess, D. T., and G. E. Schneider (1981) Advantages of polarization microscopy in horseradish peroxidase neurohistochemistry. J. Histochem. Cytochem. 29: 1448-1450.

Hollander, H., and H. Vanegas (1977) The projection from the lateral geniculate nucleus onto the visual cortex in the cat. A quantitative study with horseradish-peroxidase. J. Comp. Neurol. 173: 519-536.

Hubel, D. H., and T. N. Wiesel (1962) Receptive fields, binocular interaction and functional architecture in the cat's visual cortex. $J$. Physiol. (Lond.) 165: 559-568.

Hubel, D. H., and T. N. Wiesel (1965) Binocular interaction in the striate cortex of kittens reared with artificial squint. J. Neurophysiol. 28: 1041-1059.

Hubel, D. H., and T. N. Wiesel (1968) Receptive fields and functional architecture of monkey striatc cortex. J. Physiol. (Lond.) 195: 215243.

Hubel, D.H., and T. N. Wiesel (1972) Laminar and columnar distribution of geniculo-cortical fibers in the macaque monkey. J. Comp. Neurol. 146: 421-450.

Hubel, D. H., and T. N. Wiesel (1977) Functional architecture of macaque monkey visual cortex. Proc. R. Soc. London [Biol.] 198: $1-59$.

Hubel, D. H., T. N. Wiesel, and M. P. Stryker (1978) Anatomical demonstration of orientation columns in macaque monkey. J. Comp. Neurol. 177: 361-380.

Humphrey, A. L., M. Sur, D. J. Ulrich, and S. M. Sherman (1985) Termination patterns of individual $\mathrm{X}$ - and $\mathrm{Y}$-cell axons in the visual cortex of the cat: Projections to area 18 , to the $17 / 18$ border region, and to both areas 17 and 18. J. Comp. Neurol. 233: 190-212.

Illing, B., and H. Wässle (1979) Visualization of the HRP reaction product using the polarization microscope. Neurosci. Lett. 13:7.

Itaya, S. K., and G. W. Van Hoesen (1982) WGA-HRP as a transneuronal marker in the visual pathways of monkey and rat. Brain Res. 236: 199-204.

Itaya, S. K., P. W. Itaya, and G. W. Van Hoesen (1984) Intracortical termination of the retino-geniculo-striate pathway studied with transsynaptic tracer (wheat germ agglutinin-horseradish peroxidase) and cytochrome oxidase staining in the macaque monkey. Brain Res. 304 : 303-310.

Kalia, M., and D. Whitteridge (1973) The visual areas in the splental sulcus of the cat. J. Physiol. (Lond.) 232: 275-283.

LeVay, S., and M. P. Stryker (1979) The development of ocular dominance columns in the cat. Soc. Neurosci. Symp. 4: 883-898.

LeVay, S., D. H. Hubel, and T. N. Wiesel (1975) The pattern of ocular dominance columns in macaque visual cortex revealed by a reduced silver stain. J. Comp. Neurol. 159: 559-576.

LeVay, S., M. P. Stryker, and C. J. Shatz (1978) Ocular dominance columns and their development in layer IV of the cat's visual cortex: A quantitative study. J. Comp. Neurol. 179: 223-244.

LeVay, S., T. N. Wiesel, and D. H. Hubel (1980) The development of ocular dominance columns in normid and visually deprived monkeys. J. Comp. Neurol. 191: 1-15.

LeVay, S., M. Connolly, J. Houde, and D. C. Van Essen (1985) The complete pattern of ocular dominance stripes in the striate cortex and visual field of the macaque monkey. J. Neurosci. 5: 486-501.

Livingstone, M. S., and D. H. Hubel (1984) Anatomy and physiology of a color system in the primate visual cortex. J. Neurosci. 4: 309 356.

Malpeli, J. G., and F. H. Baker (1975) The representation of the visual field in the lateral geniculate nucleus of Macaca mulatta. J. Comp. Neurol. 161: 569-594.

Mesulam, M. M. (1978) Tetramcthyl benzidine for horseradish peroxidase neurohistochemistry: A non-carcinogenic blue reaction product with superior sensitivity for visualizing neural afferents and efferents. J. Histochem. Cytochem. 26: 106-117.

Mower, G. D., C. J. Caolan, W. G. Christen, and F. H. Duffy (1985) Dark-rearing prolongs physiological but not anatomical plasticity of the cat visual cortex. J. Comp. Neurol. 235: 448-466.

Olavarria, J., and R. C. Van Sluyters (1983) The pattern of visual 
callosal connections in the cat as revealed in tangential sections of the unfolded cortex. Soc. Neurosci. Abstr. 9: 155.

Olavarria, J., and R. C. Van Sluyters (1985) Unfolding and flattening the cortex of gyrencephalic brains. J. Neurosci. Methods 15: 191202.

Olavarria, J., and R. C. Van Sluyters (1986) HRP-TMB histochemistry: Brief rinsing of histological sections in low $\mathrm{pH}$ solution reduces non-specific precipitate. J. Histotechnol. 9: 111.

Palmer, L. A., A. C. Rosenquist, and R. J. Tusa (1978) The retinotopic organization of lateral suprasylvian visual areas in the cat. J. Comp. Neurol. 177: 237-256.

Polley, E. H., and R. W. Guillery (1980) An anomalous uncrossed retinal input to lamina $A$ of the cat's dorsal lateral geniculate nucleus. Neuroscience 5: 1603-1608.

Rolls, E. T., and A. Cowey (1970) Topography of the retina and striate cortex and its relationship to visual acuity in rhesus monkeys and squirrel monkeys. Exp. Brain Res. 10: 298-310.

Rowe, M. H., and B. Dreher (1982) Retinal W-cell projections to the medial interlaminar nucleus in the cat: Implications for ganglion cell classification. J. Comp. Neurol. 204: 117-133.

Ruda, M., and J. D. Coulter (1982) Axonal and transneuronal transport of wheat germ agglutinin demonstrated by immunocytochemistry. Brain Res. 249: 237-246.

Shatz, C. J., and M. P. Stryker (1978) Ocular dominance in layer IV of the cat's visual cortex and the effects of monocular deprivation. J. Physiol. (Lond.) 281: 267-283.

Shatz, C. J., S. Lindstrom, and T. N. Wiesel (1977) The distribution of afferents representing the right and left eyes in the cat's visual cortex. Brain Res. 131: 103-116.

Silverman, M. S., K. B. H. Tootell, and R. L. DeValois (1982) A comparison of ocular dominance patterns in cat and monkey. Invest. Ophthalmol. Vis. Sci. ARVO Abstr. Suppl. 22: 12.

Specht, S. C., and B. Grafstein (1977) Axonal transport and transneuronal transfer in mouse visual system following injection of $\left[{ }^{3} \mathrm{H}-\right]$ fucose into the eye. Fxp. Neurol. 54: 352-368.

Spencer, R. F., H. Baker, and R. Baker (1982) Evaluation of wheat germ agglutinin immunohistochemistry as a neuroanatomical method for retrograde, anterograde and anterograde transsynaptic labelling in the cat visual and oculomotor systems. Soc. Neurosci. Abstr. 8: 785.

Stone, J., and B. Dreher (1973) Projection of X- and Y-cells of the cat's lateral geniculate nucleus to areas 17 and 18 of visual cortex. J. Neurophysiol. 36: 551-567.

Stryker, M. P. (1982) Role of afferent activity in the development of ocular dominance columns. Neurosci. Res. Prog. Bull. 20: 540-549.

Swindale, N. V. (1981) Absence of ocular dominance patches in darkreared cats. Nature 290: 332-333.

Talbot, S. A., and W. H. Marshall (1941) Physiological studies on neural mechanisms of visual localization and discrimination. Am. J. Ophthalmol. 24: 1255-1264.

Tieman, S. B., and N. Tumosa (1983) [ $\left.{ }^{14} \mathrm{C}-\right] 2-$ Deoxyglucose demonstration of the organization of ocular dominance in areas 17 and 18 of the normal cat. Brain Kes. 267: 35-46.

Tusa, R. J., and L. A. Palmer (1980) Retinotopic organization of areas 20 and 21 in the cat. J. Comp. Neurol. 193: 147-164.

Tusa, R. J., L. A. Palmer, and A. C. Rosenquist (1978) The retinotopic organization of area 17 (striate cortex) in the cat. J. Comp. Neurol. 177: 213-236.

Tusa, R. J., A. C. Rosenquist, and L. A. Palmer (1979) Retinotopic organization of areas 18 and 19 in the cat. J. Comp. Neurol. 185: 657-678.

Vakkur, G. J., P. O. Bishop, and W. Kozak (1963) Visual optics in the cat, including posterior nodal distance and retinal landmarks. Vision Res. 3: 289-314.

Van Essen, D. C., and J. H. R. Maunsell (1980) Two-dimensional maps of the cerebral cortex. J. Comp. Neurol. 191: 255-281.

Van Essen, D. C., W. T. Newsome, and J. H. R. Maunsell (1984) The visual field representation in striate cortex of the macaque monkey: Asymmetries, anisotropies, and individual variability. Vision Res. 24: 429-448.

Woolsey, C. N. (1971) Comparative studies on cortical representation of vision. Vision Res. Suppl. 3: 365-382. 